\title{
Poliomyelitis-related deformities successfully treated with reconstructing and lengthening lower limb surgeries over a period of 5 years: Challenging approaches in a limited-resources country
}

\author{
Marah Mansour ${ }^{1}$, Khaled Harmouch ${ }^{2}$, Tamim Alsuliman ${ }^{3}$, and Abdulmouain Zrek ${ }^{4}$ \\ ${ }^{1}$ Faculty of Medicine, Tartous University \\ ${ }^{2}$ Near East University Faculty of Medicine \\ ${ }^{3}$ Saint-Antoine Hospital, AP-HP, Sorbonne University \\ ${ }^{4}$ Alrazi Governmental hospital
}

October 3, 2021

\begin{abstract}
Poliomyelitis is a viral infection that may lead to paralysis or death. Paralysis can lead to skeletal and joint deformities. Typical manifestations include equinos cavus and tibial shortening. We report a polio case presented with right equinus foot, clawing in the right great toe, and shortening in the right tibia.
\end{abstract}

\section{Hosted file}

Main document.docx available at https://authorea.com/users/439198/articles/540217poliomyelitis-related-deformities-successfully-treated-with-reconstructing-andlengthening-lower-limb-surgeries-over-a-period-of-5-years-challenging-approaches-ina-limited-resources-country 


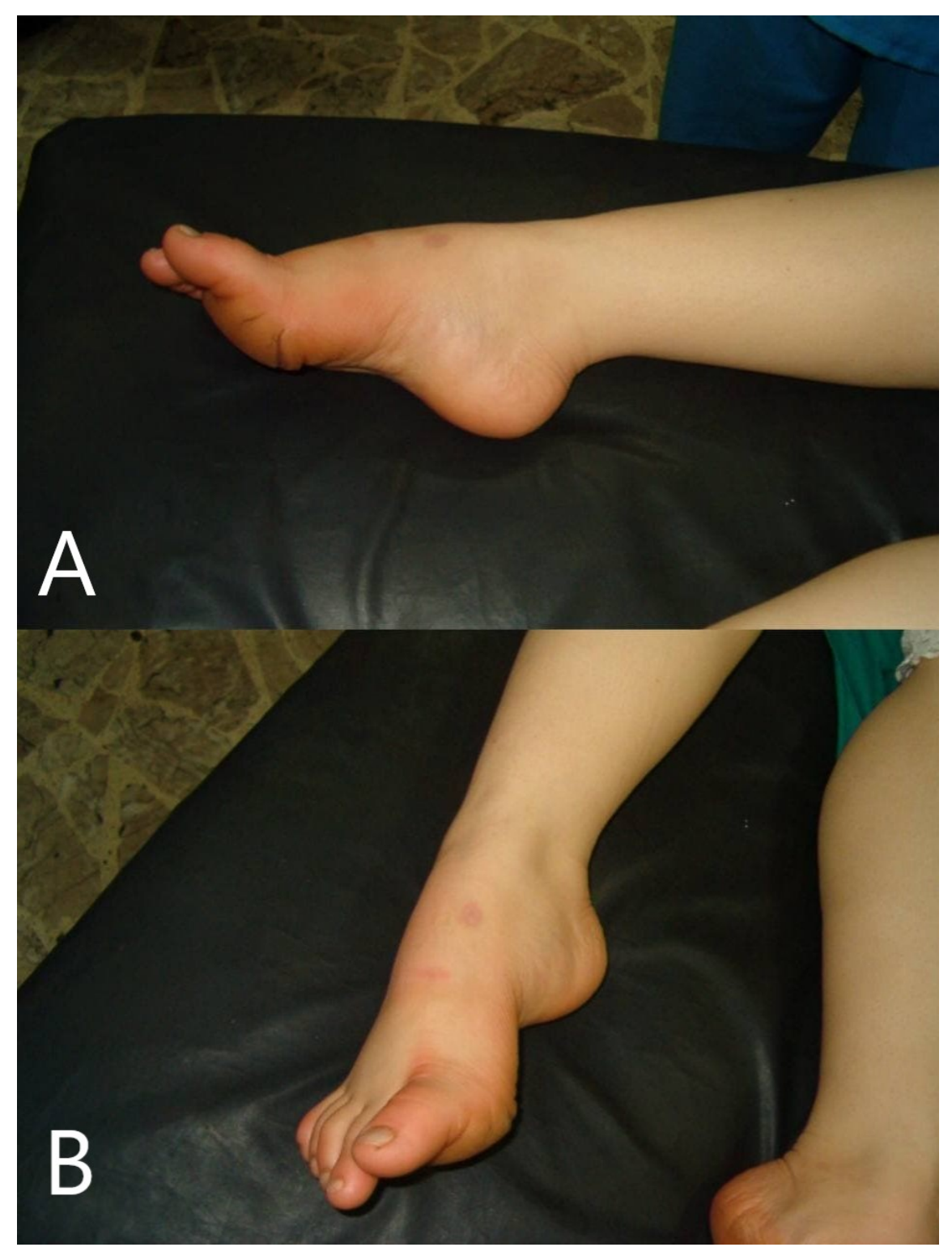




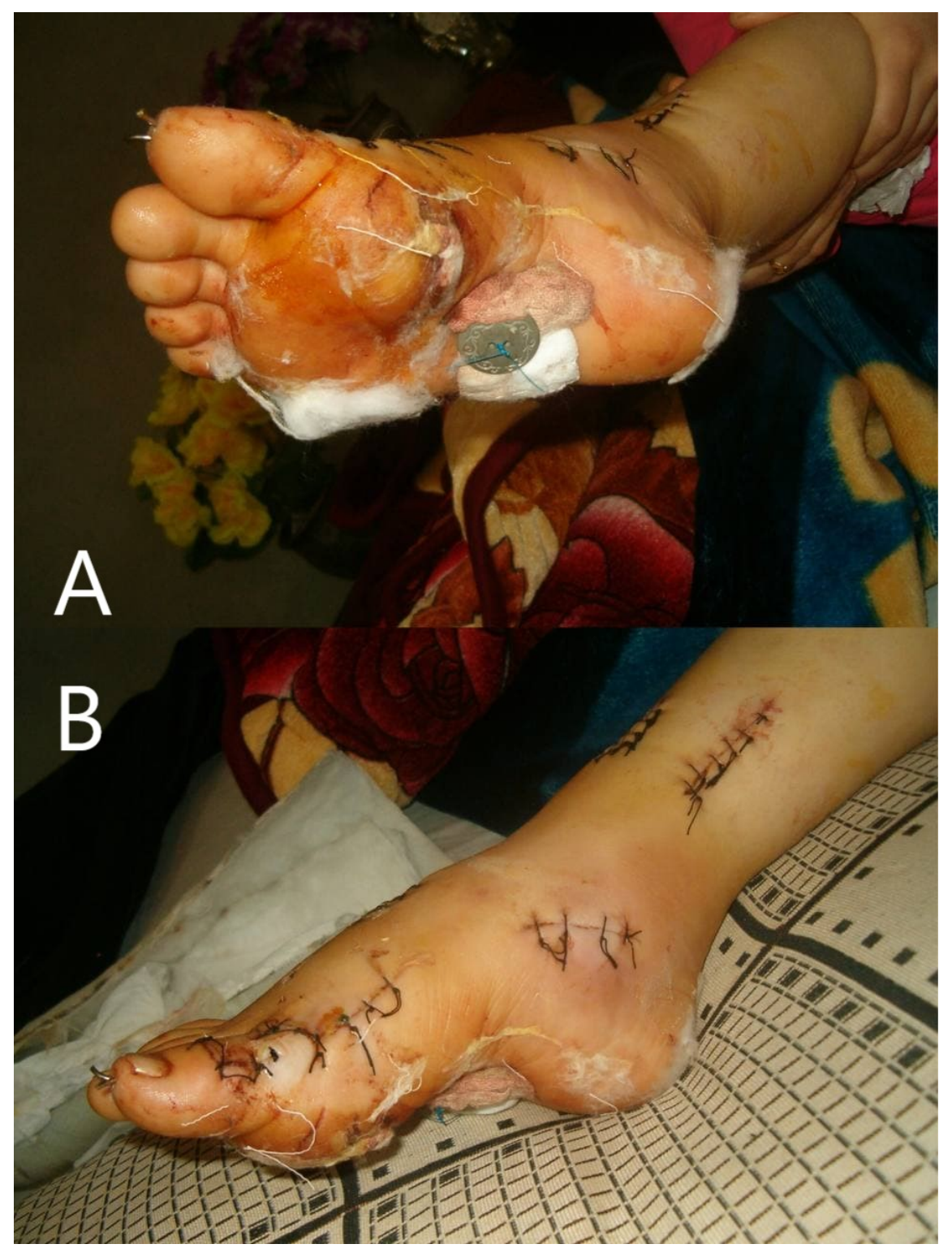




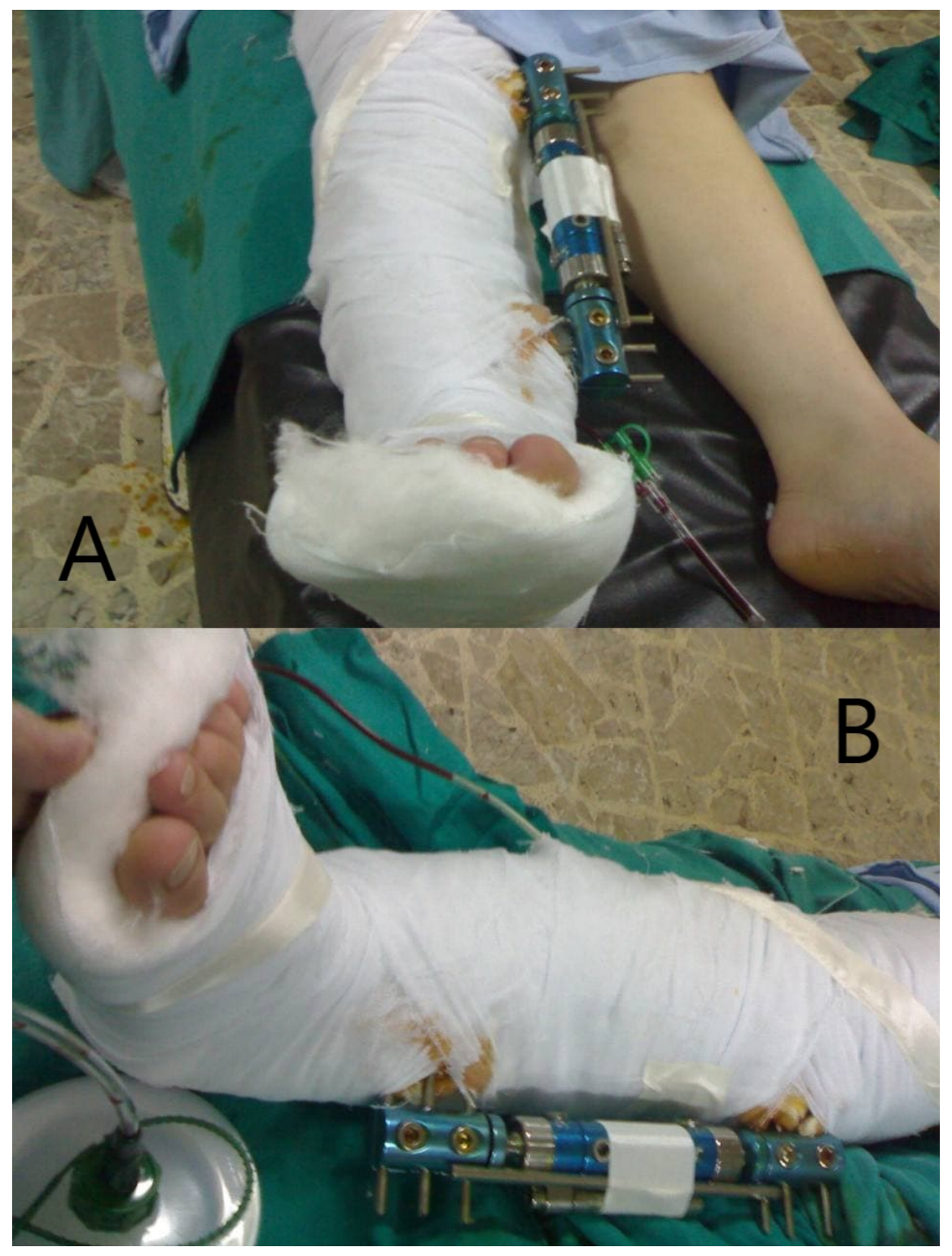



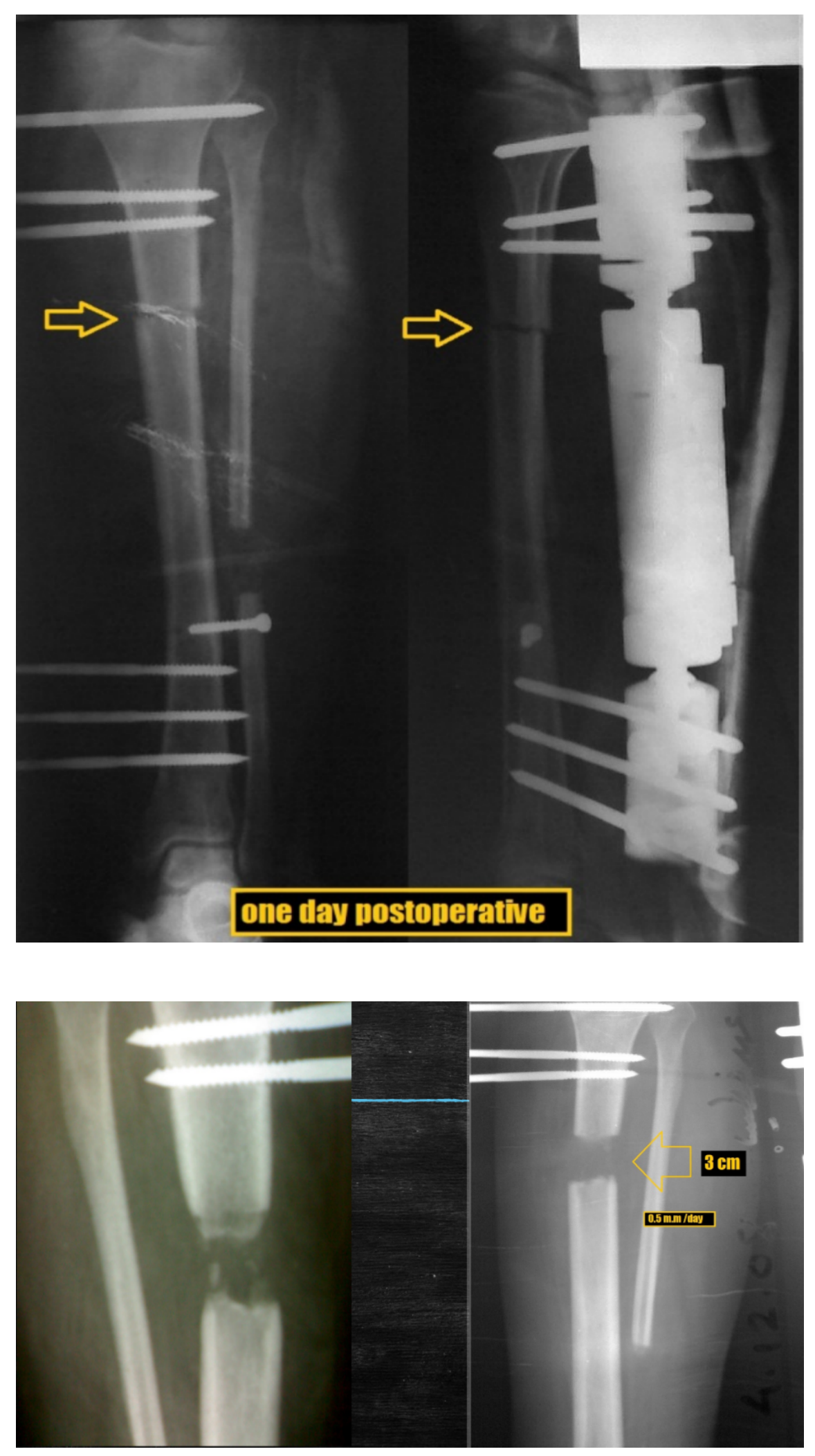


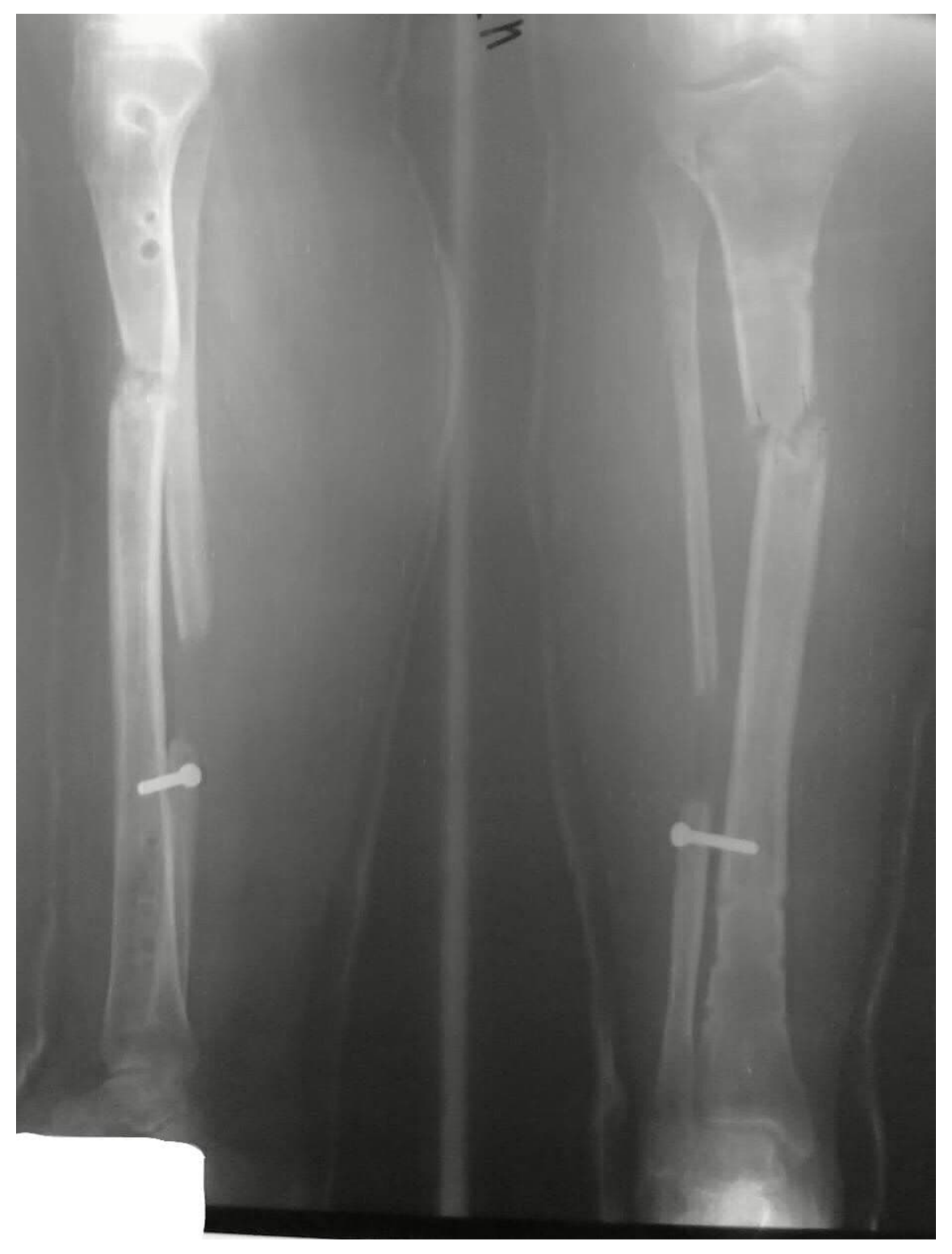




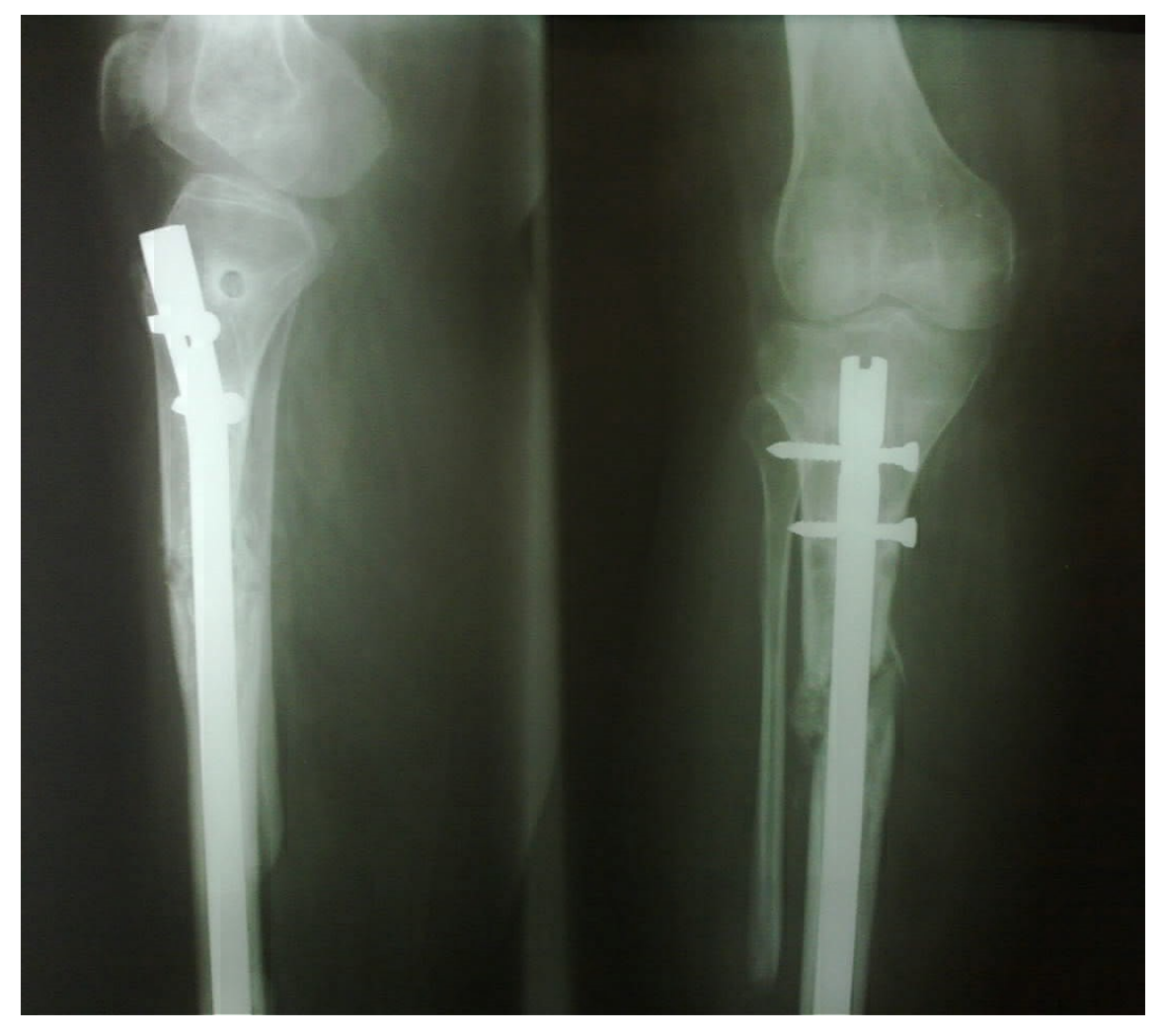




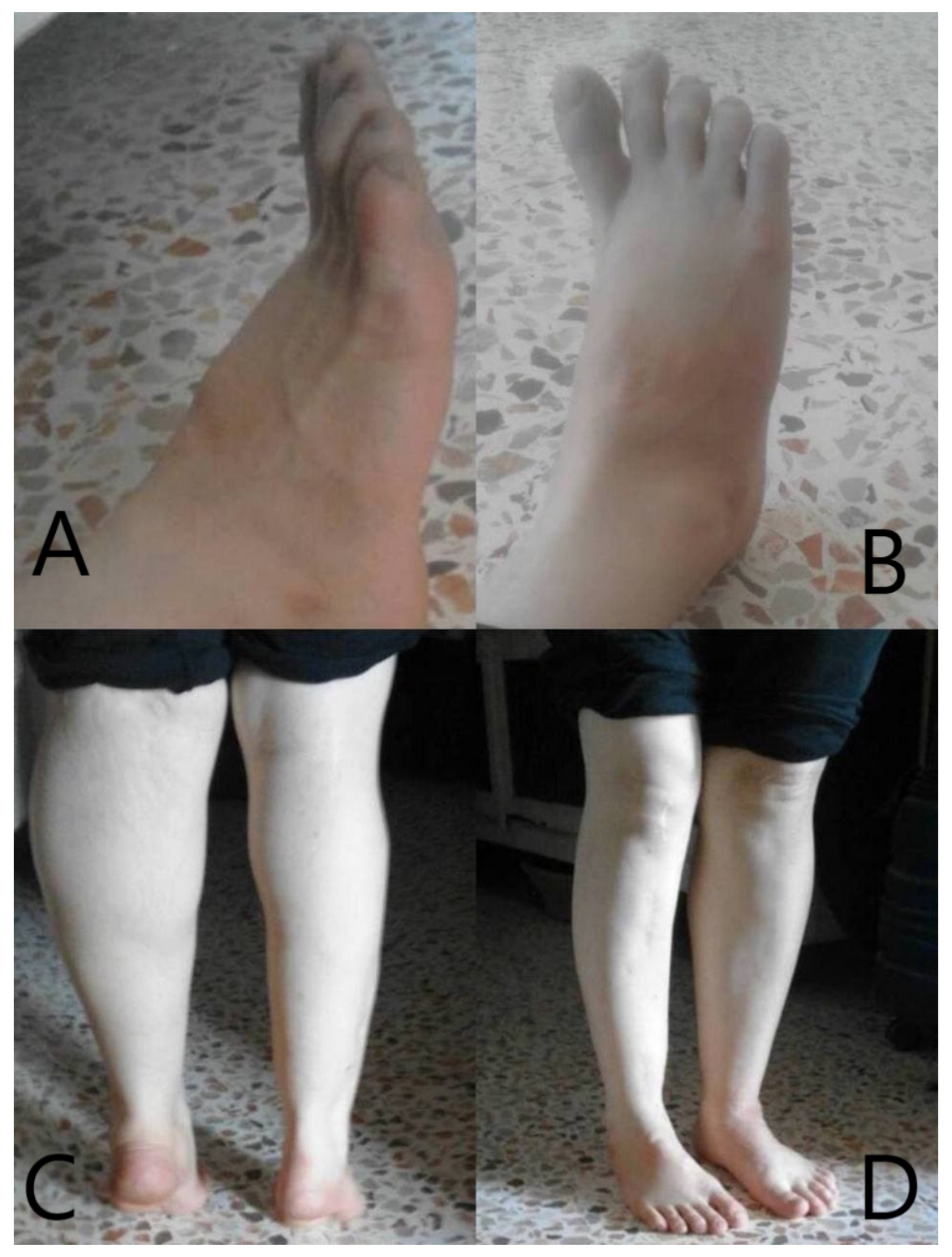

